\title{
Análise de um Modelo Discreto-Geométrico para o Problema da Propagação da Podridão em MaÇãs em Conexão com Progressões e Geometria no ENSINo MÉdio *
}

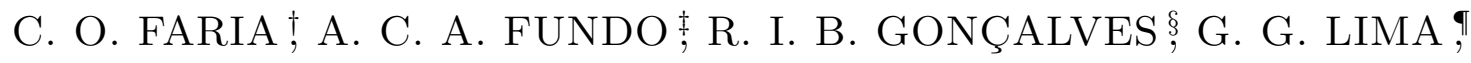 \\ J. P. B. de SOUZA $\|_{\text {e L. S. S. MARTINO }}^{* *}$
}

\begin{abstract}
Resumo
Neste artigo, apresentamos uma nova abordagem construtivista para o modelo discreto-geométrico, proposto por BASSANEZI (2012), aplicado ao problema da propagação da podridão de maçãs confinadas em uma caixa retangular. Tendo como auxílio didático a montagem de uma maquete, construída com bolas de isopor, para simular o efeito de propagação do apodrecimento das maçãs em uma caixa, o modelo surge naturalmente. Esta proposta pode ser aplicada como uma atividade em turmas do Ensino Médio, apresentando aos alunos os preceitos básicos da Modelagem Matemática. O intuito de realizar esse experimento é levar para os estudantes uma nova visão da Matemática, mostrando conceitos básicos do Ensino Médio como progressões aritméticas e geometria sendo aplicados juntos na resolução do mesmo problema. E, com isso, mostrar para esses alunos como os conceitos matemáticos se interligam e podem ser muito mais interessantes quando estudados juntos.
\end{abstract}

\section{Introdução}

A Matemática sempre esteve presente na vida do homem, desde as experiências mais simples como contar e comprar, até nas descobertas mais revolucionárias. Nesse contexto, o ensino da matemática é iniciado logo nos primeiros segmentos escolares. Porém, nota-se cada vez mais que o ensino-aprendizagem da Matemática no Ensino Médio tem sido motivo de preocupação dos professores e dos próprios alunos. Muito se tem discutido sobre a falta de interesse dos alunos do Ensino Básico das escolas do Brasil quando o assunto é Matemática e, ao mesmo tempo, é inegável que esta área do conhecimento está atrelada ao crescimento da ciência e a economia de um país.

Palavras chave: Modelagem Matemática, Ensino de Matemática, Ensino Médio, Abordagem Construtivista

${ }^{\dagger}$ Departamento de Análise Matemática, Instituto de Matemática e Estatística - IME, Universidade do Estado do Rio de Janeiro - UERJ, Rio de Janeiro, RJ, Brasil, e-mail: cofaria@ime.uerj.br

${ }^{\ddagger}$ IME/UERJ, e-mail: carol-norfolk@hotmail.com

§IME/UERJ, e-mail: ruthisabelab@gmail.com

ฯIME/UERJ, e-mail: gabrielgonzaga@outlook.com

"IME/UERJ, e-mail: joaopaulo251296@gmail.com

**Departamento de Matemática, Colégio Pedro II, Polo São Cristovão, Rio de Janeiro, RJ, e-mail: lulismartino@gmail.com

D.O.I.: https://doi.org/10.12957/cadmat.2019.47126 
O ensino da Matemática em muitas escolas no Brasil não possui foco de aplicação fora das salas de aula. Geralmente, a disciplina é mostrada como uma ferramenta repleta de fórmulas que serão utilizadas para resolução de diversos problemas do dia a dia. No entanto, na maioria das vezes, se inventam "situações do cotidiano" totalmente abstratas e que provocam o aumento do desinteresse nos alunos em aprender sobre a disciplina. De acordo com Gontijo (2007):

O trabalho pedagógico com a matemática, na maioria das escolas, tem sido marcado pela fragmentação, descontextualização e ensino mecânico. Essa realidade tem gerado desinteresse e indiferença em relação a este componente curricular, produzindo ao longo da história escolar dos alunos um sentimento de fracasso e incapacidade para compreender e resolver problemas matemáticos.

Além disso, sabe-se que o raciocínio lógico-matemático deve ser desenvolvido com o objetivo de criar maior facilidade para as pessoas executarem as tarefas de seu cotidiano. Deste contraste, surge um dos grandes questionamentos de um educador matemático: como romper o estigma desta disciplina ser comumente vista como chata ou frustrante, e mostrar o lado encantador e curioso que dela?

Devido às indagações levantadas anteriormente, pesquisas são realizadas em diversos campos da matemática com o intuito de responder esses tipos de questões. Dentre esses campos, destaca-se a Modelagem Matemática - um processo que consiste na descrição matemática, em sua forma mais aproximada possível, de um fenômeno real relacionado à qualquer natureza do âmbito científico. Com a Modelagem Matemática, a disciplina pode ser ensinada através da resolução de problemas que fazem parte da vida de qualquer grupo de alunos, dando utilidade a todas as ferramentas consideradas por eles isoladas e sem sentido. Segundo Barbosa:

"[...] a Modelagem possibilita o envolvimento dos alunos nos problemas, não só da própria matemática, mas nos problemas do mundo real, ou seja, estudar matemática não só pela matemática, mas correlacionando os conhecimentos matemáticos com os problemas do dia a dia do aluno ou da comunidade escolar, ou ainda, os problemas do dia a dia são impulsionadores para o aprendizado dos conteúdos de matemática. Nesse sentido, com o uso de Modelagem Matemática, há uma grande propensão em auxiliar os alunos a apreciar a Matemática."(BARBOSA, 2012, p.15)

Motivado por este princípio de utilizar a Modelagem Matemática como uma ferramenta didática mais interessante, e trazer um aprendizado significativo no Ensino Básico, em 2016, na Universidade do Estado do Rio de Janeiro (UERJ), foi iniciado o projeto de pesquisa "A Modelagem Matemática aplicada na educação do Ensino Médio: uma ferramenta atual"pela professora Cristiane Faria, para que alunos de licenciatura de Matemática obtivessem essa experiência. Neste projeto, seguindo a metodologia da Modelagem Matemática, o tema escolhido pelo grupo de alunos que faz parte do projeto é estudado com o propósito de gerar materiais didáticos para serem utilizados na Educação Básica. 
Neste artigo relatamos a experiência da pesquisa realizada no ano de 2017. A partir do estudo de um capítulo do livro Temas e Modelos, de Rodney J. Bassanezi (BASSANEZI, 2012), foi visto que com um dos modelos matemáticos teóricos do autor, era possível criar um material didático para o Ensino Médio explorando conceitos aprendidos neste segmento. O diferencial do material didático criado neste projeto é que, ao invés de um modelo téorico voltado para a matemática aplicada, um modelo construtivista é apresentado (feito com a confecção de uma maquete), visando sua utilização na Educação e permitindo a abordagem dos tópicos vistos no Ensino Médio de forma interligada.

A atividade dissertada neste artigo tem foco em mostrar como a matemática pode ser apresentada de forma interessante, através da Modelagem Matemática, quebrando o paradigma já conhecido do Ensino Matemático no Brasil. Como pontua D'Ambrósio (1989), em nenhum instante no processo escolar, as aulas de matemática geram momentos no qual o aluno deve ser criativo, e esteja motivado à solucionar um problema pelo desafio em si, ou por causa da curiosidade criada pela situação. Para isto, o objeto de estudo apresentado analisa o processo de apodrecimento de maçãs, um problema real que, a partir de determinadas condições e hipóteses, é possível ser descrito usando conceitos e áreas da Matemática aprendidos no Ensino Médio, como progressão aritmética, geometria plana e espacial.

Diante disso, este artigo seguirá abordando como se deu o surgimento do problema apresentado. Em seguida, a aula para a montagem da maquete será descrita, abordando os materiais necessários e os processos envolvidos nesta construção. Feito isso, a metodologia utilizada para tal confecção será desenvolvida, mostrando os modelos gerados e os conteúdos matemáticos explorados. Na próxima etapa, será mostrada a recepção dos alunos ao realizarem a atividade e o que ela representou para eles. A partir das percepções dos alunos, uma conclusão será elaborada a partir dos dados obtidos.

\section{O Problema e a Proposta}

O problema real escolhido para este trabalho foi retirado do livro "Temas e Modelos", de Rodney J. Bassanezi (BASSANEZI, 2012). Em resumo, seria a seguinte situação: Suponha que um hortifruti acaba de receber a sua compra semanal de verduras e frutas. No entanto, as maçãs ainda não serão expostas na bancada. Elas continuarão guardadas na caixa que vieram estocadas. Supondo que dentro desta caixa, bem no centro, tem uma maçã podre em quanto tempo todas as maçãs da caixa estarão perdidas?. Para que o modelo tome forma precisamos enunciar algumas hipóteses iniciais:

- O formato da caixa estudado será cúbica, além da mesma ser dividida em camadas horizontais sobrepostas de maçãs;

- a maçã que está podre inicialmente está localizada no centro da camada central e o contágio da doença é feito, apenas, através do contato;

- cada dia será consideradoo como sendo um estágio do processo;

- considera-se também que em 12 dias, $80 \%$ das maçãs estarão totalmente contaminadas. 
Logo, levando em consideração o formato da caixa ser cúbico e existir 2996 maçãs dentro dela, chegase a conclusão que cada lado da caixa corresponde aproximadamente à raiz cúbica de 2996, ou seja, entre 14 e 15 frutas (como mostra a Figura 1).

Figura 1: Maçãs empacotadas em um bin.

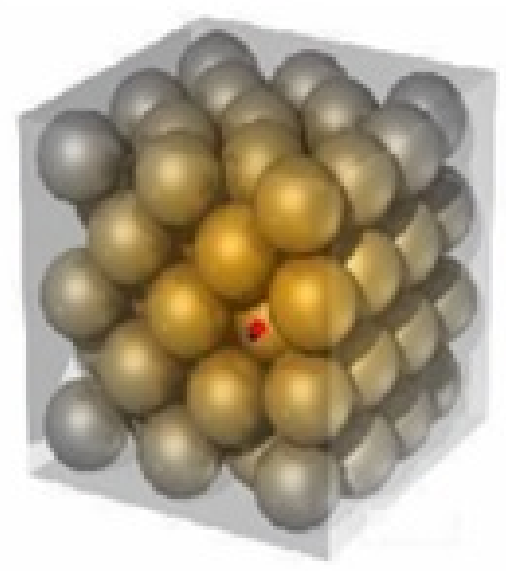

Fonte: (Bassanezi,2012)

Bassanezi propôs quatro modelos: dois contínuos e dois discretos. Os modelos contínuos foram formalizados através de equações diferenciais ordinárias. Cada um deles é submetido a diferentes condições iniciais e, com essa diferença, podemos concluir que essa alteração influencia diretamente na análise e predição dos resultados obtidos do processo de apodrecimento de maçãs, tornando-se um fator muito importante a ser considerado.

Nos modelos discretos, foi considerado que as maçãs contidas no bin (caixa de madeira cúbica) estão sobrepostas em camadas. No primeiro modelo, usamos a geometria euclidiana para entender a propagação da doença e a partir de agora, o chamaremos de modelo discreto-geométrico. Já no segundo modelo, um esquema de diferenças é proposto a partir do modelo contínuo e uma relação de recorrência, definindo melhor a forma que a propagação da doença ocorre, é encontrada.

Como o modelo discreto-geométrico utiliza apenas tópicos da matemática vistos no Ensino Básico, como progressões aritméticas, geometria plana e geometria espacial, este foi o escolhido para a nossa pesquisa. Desta forma, a construção de uma maquete, simulando o fenômeno em uma caixa cúbica contendo 2996 maçãs, é proposta para que o alunado possa construir seu modelo instintivamente.

A ideia da construção da maquete como um material didático surgiu durante as reuniões dos autores deste artigo, mostrando a originalidade desta, e transportando a abordagem de matemática aplicada descrita por BASSANEZI (2012) para uma perspectiva direcionada ao ensino de matemática. 


\section{Montagem da Maquete}

A partir das hipóteses iniciais vistas na Seção 2, inicia-se a montagem da maquete representando o problema. A proposta é que os alunos irão confeccioná-la em sala de aula, e construirão uma miniatura do modelo até o quinto estágio de propagação, com um número reduzido de esferas, totalizando 192 bolas de isopor. Como recurso didático, cada estágio da propagação é simbolizado com uma cor diferente. Desta forma, as cores preta, marrom, azul, verde e amarela representam o primeiro, segundo, terceiro, quarto e quinto estágio, respectivamente. Na Figura 2 é ilustrado o que ocorre na primeira camada nos cinco primeiros estágios. A produção deste material segue três etapas que serão descritas em seguida.

Figura 2: Modelo da camada central.

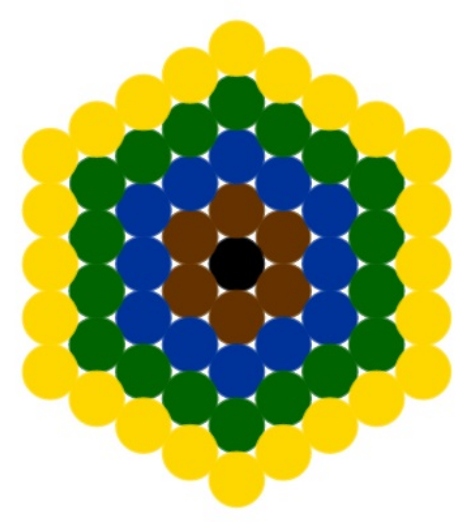

fonte : Autoria Própria

\subsection{Explicação Geométrica}

Se o formato de cada uma das maçãs for considerado como esférico e sabendo que pelas hipóteses cada fruta contamina outra apenas através do contato; havendo apenas uma maçã podre inicialmente, no mesmo plano horizontal desta, apenas seis frutas serão contaminadas no primeiro estágio, já que o número máximo de frutas tangenciando uma outra é seis, conforme vemos na Figura 3. Esta conclusão parte da ideia de termos o maior número de maçãs tangenciando uma outra. Por uma análise geométrica, percebe-se que pelas esferas serem congruentes, é possível construir um triângulo equilátero conectando os centros de três esferas tangentes, tendo em vista que o lado do triângulo formado mede duas vezes o raio de cada esfera, como na Figura 4. Com isso, é fácil notar que, ao adicionar mais quatro esferas tangentes à central, forma-se um hexágono com os vértices nos centros das esferas. 
Figura 3: Hexágono formado por todas as maçãs que tangenciam uma determinada fruta.

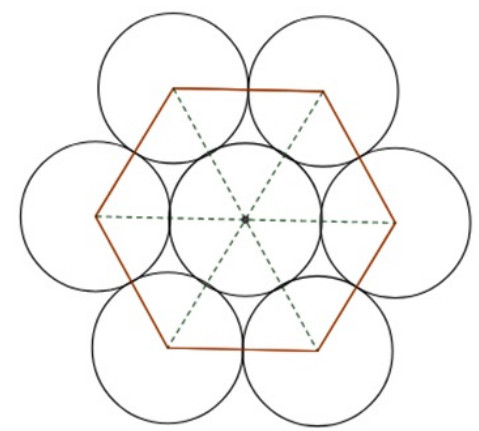

fonte : Autoria Própria

Figura 4: Maçãs adjacentes localizadas em uma mesma camada horizontal.

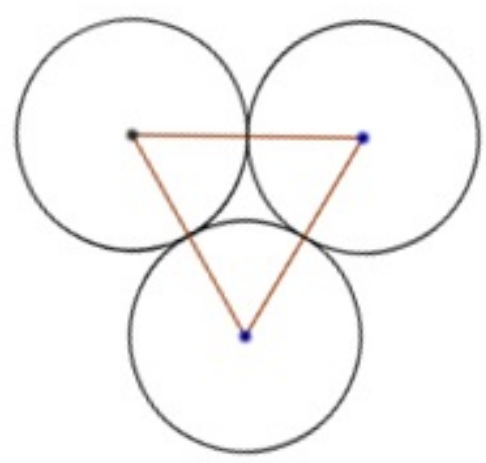

fonte : Autoria Própria

\subsection{Camada Central}

Agrupando seis esferas de isopor em volta da contaminada inicialmente, como na Figura 3, pode ser visto o que ocorre na camada central da caixa entre o estágio 0 e o estágio 1. Em seguida, essas maçãs contaminadas, em contato com outras maçãs, contagiam aquelas que estão em contato com essas e assim sucessivamente. A cada estágio, é possível visualizar que as maçãs contaminadas formam hexágonos encaixantes, isto é, em todos os estágios, ao longo da camada central, as maçãs apodrecidas formam hexágonos semelhantes aos seus respectivos estágios anteriores, porém de lado maior ao que o antecede. Como cada lado dela possui 14 ou 15 unidades de maçãs, isto acontece até o estágio de número 7, que é quando o contágio atinge as paredes da caixa. 


\subsection{Camadas Superiores}

Agora temos que avaliar as outras camadas. A maçã podre inicialmente também está em contato com três maçãs na camada superior e três na inferior, ou seja, essas frutas também são contaminadas. Sendo assim, no primeiro estágio além das seis maçãs na camada central horizontal, foram contaminadas mais três na camada superior imediata e três na camada inferior imediata. Porém, para facilitar a montagem da maquete, é levado em consideração apenas o que acontece nas camadas superiores da camada central, já que o problema ocorre de forma simétrica.

Desta forma, o estágio de contágio 1 é concluído, já que todas as maçãs que tangenciam a podre inicial também estão contaminadas. As maçãs apodrecidas no estágio 1 darão continuidade ao processo, contaminando todas aquelas que as tocam, dando início ao estágio 2. Dessa forma, pode-se deduzir como a doença se propaga na caixa, a partir de raciocínio análogo, ilustrado na Figura 5.

Figura 5: Modelos das segundas camadas.

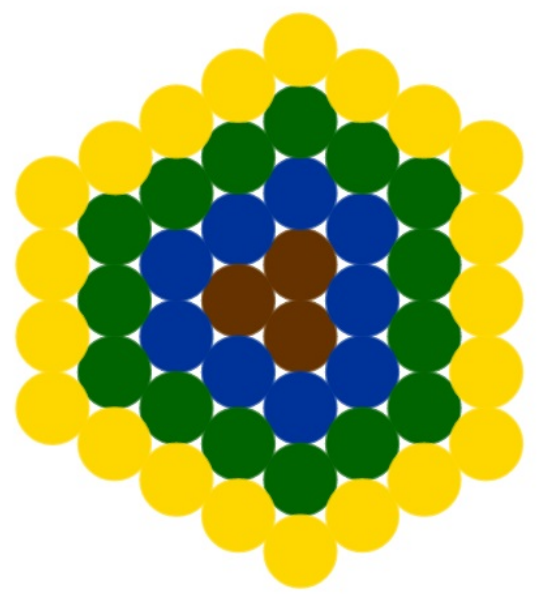

fonte : Autoria Própria

A partir deste momento, como já é conhecida a dinâmica do apodrecimento destas frutas até o terceiro estágio, analisa-se, matematicamente, cada uma das camadas, de forma que seja possível criar um modelo matemático para este fenômeno.

O início desta análise origina-se a partir da camada horizontal situada no centro da caixa. Ao observá-la, é possível verificar algum padrão na camada central? Nota-se que a partir do estágio 2 , na camada horizontal central, a quantidade de maçãs apodrecidas em um estágio $n$ equivale a seis unidades a mais do que a do seu estágio anterior $(n-1)$. Deste modo, observa-se que a quantidade de maçãs contaminadas em cada estágio, a partir do primeiro, sempre forma uma progressão aritmética. Na camada horizontal central, é possível estabelecer uma relação de recorrência que determina a quantidade 
de maçãs apodrecidas $\left(A_{n}\right)$ até o estágio $n$.

$$
\begin{aligned}
& A_{0}=1 \\
& A_{1}=A_{0}+6 \cdot 1=1+6=7 \\
& A_{2}=A_{1}+6 \cdot 2=1+6+12=7+12=19 \\
& A_{3}=A_{2}+6 \cdot 3=1+6+12+18=19+18=37
\end{aligned}
$$

Observando o padrão acima, é possível estabelecer a seguinte fórmula de recorrência

$$
\left\{\begin{array}{l}
A_{n}=A_{n-1}+6 n, \\
A_{0}=1
\end{array}\right.
$$

Repare que a sequência de resultados acima foi gerada através da equação de recorrência (3.1), ou seja, é necessário sempre conhecer o resultado anterior para gerar um novo. Desenvolvendo os termos desta relação, encontra-se uma fórmula geral para descobrir a quantidade de maçãs podres até um estágio $n$ qualquer, sem necessidade de conhecer a quantidade de frutas contaminadas até o estágio anterior:

$$
\begin{aligned}
& A_{0}=1 \\
& A_{1}=A_{0}+6 \cdot 1=A_{0}+3 \cdot 1 \cdot(1+1)=7 \\
& A_{2}=A_{0}+18=A_{0}+3 \cdot 2 \cdot(2+1)=19 \\
& A_{3}=A_{0}+36=A_{0}+3 \cdot 3 \cdot(3+1)=37
\end{aligned}
$$

Observando o padrão acima, é possível estabelecer a seguinte fórmula de recorrência

$$
A_{n}=A_{0}+3 \cdot n \cdot(n+1), \quad \text { para } \quad 1 \leq n \leq 7
$$

Na equação (3.2), 7 é o número máximo para $n$, já que, como foi visto anteriormente, a contaminação de maçãs na camada horizontal central toma forma de hexágonos encaixantes, e por isso, em $n=7$, as maçãs tocarão as paredes da caixa.

E quanto às segundas camadas? Existe alguma relação entre a quantidade de maçãs adoecidas em diferentes estágios delas? Experimentalmente, é possível ver que existe um espaço não ocupado sobre cada grupo de três maçãs adjacentes localizadas na camada central. Sendo assim, as maçãs encontradas nas camadas imediatamente acima e abaixo da central, ou seja, nas segundas camadas, serão dispostas em espaços intercalados, de forma que existam três maçãs alocadas acima da primeira maçã podre e que serão contaminadas no estágio 1 .

A partir do estágio 2, percebe-se que nas segundas camadas, a quantidade de maçãs apodrecidas em um estágio $n$ equivale a seis unidades a mais do que seu estágio anterior $(n-1)$. Ou seja, podemos estabelecer uma relação de recorrência que determina a quantidade de maçãs no estágio $n$ apodrecidas nas camadas superiores $\left(P_{n}\right)$, e obtem-se:

$$
\begin{aligned}
& P_{2}=3+6=9 \\
& P_{3}=9+6=15
\end{aligned}
$$


Seja $P_{n}$ o número de novas maçãs adoecidas no estágio $n$, cria-se uma progressão aritmética que estabelece a quantidade de novas maçãs apodrecidas em cada estágio nesta camada, e tem-se:

$$
\left\{\begin{array}{l}
P_{n}=P_{n-1}+6, \quad 2 \leq n \leq 7 \\
P_{1}=3
\end{array}\right.
$$

Novamente, o problema retorna para uma equação de recorrência, fazendo que um termo dependa do seu anterior. Porém, é possivel estabelecer uma fórmula geral, gerada a partir da equação (3.3) de recorrência:

$$
P_{n}=3 \cdot(2 n-1) \quad \text { para } \quad 1 \leq n \leq 7
$$

Seguindo a lógica apresentada até então, a equação (3.4) representa mais uma fórmula de recorrência, onde consegue-se encontrar padrões nas camadas seguintes.

É possível determinar a quantidade de maçãs que adoecerão no estágio seguinte? A Tabela 1, encontrada em BASSANEZI(2012), sintetiza os dados obtidos durante o processo de propagação da doença até o $13^{\circ}$ estágio, onde todas as 2996 maçãs estariam totalmente contaminadas. $E_{n}$ e $C_{n}$ simbolizam estágios e camadas, respectivamente.

Tabela 1: Tabela da quantidade de maçãs contaminadas por estágio

\begin{tabular}{||c|cccccccccccccc||c||}
\hline \hline & $\mathrm{E}_{0}$ & $\mathrm{E}_{1}$ & $\mathrm{E}_{2}$ & $\mathrm{E}_{3}$ & $\mathrm{E}_{4}$ & $\mathrm{E}_{5}$ & $\mathrm{E}_{6}$ & $\mathrm{E}_{7}$ & $\mathrm{E}_{8}$ & $\mathrm{E}_{9}$ & $\mathrm{E}_{10}$ & $\mathrm{E}_{11}$ & $\mathrm{E}_{12}$ & $\mathrm{E}_{13}$ & Total \\
\hline $\mathrm{C}_{7}$ & 0 & 0 & 0 & 0 & 0 & 0 & 0 & 48 & 27 & 33 & 39 & 45 & 4 & 0 & 196 \\
$\mathrm{C}_{6}$ & 0 & 0 & 0 & 0 & 0 & 0 & 37 & 24 & 30 & 36 & 42 & 20 & 12 & 3 & 204 \\
$\mathrm{C}_{5}$ & 0 & 0 & 0 & 0 & 0 & 27 & 21 & 27 & 33 & 39 & 45 & 4 & 0 & 0 & 196 \\
$\mathrm{C}_{4}$ & 0 & 0 & 0 & 0 & 19 & 18 & 24 & 30 & 36 & 42 & 20 & 12 & 3 & 0 & 204 \\
$\mathrm{C}_{3}$ & 0 & 0 & 0 & 12 & 15 & 21 & 27 & 33 & 39 & 45 & 4 & 0 & 0 & 0 & 196 \\
$\mathrm{C}_{2}$ & 0 & 0 & 7 & 12 & 18 & 24 & 30 & 36 & 42 & 20 & 12 & 3 & 0 & 0 & 204 \\
$\mathrm{C}_{1}$ & 0 & 3 & 9 & 15 & 21 & 27 & 33 & 39 & 45 & 4 & 0 & 0 & 0 & 0 & 196 \\
$\mathrm{C}_{0}$ & 1 & 6 & 12 & 18 & 24 & 30 & 36 & 42 & 20 & 12 & 3 & 0 & 0 & 0 & 204 \\
$\mathrm{C}_{-1}$ & 0 & 3 & 9 & 15 & 21 & 27 & 33 & 39 & 45 & 4 & 0 & 0 & 0 & 0 & 196 \\
$\mathrm{C}_{-2}$ & 0 & 0 & 7 & 12 & 18 & 24 & 30 & 36 & 42 & 20 & 12 & 3 & 0 & 0 & 204 \\
$\mathrm{C}_{-3}$ & 0 & 0 & 0 & 12 & 15 & 21 & 27 & 33 & 39 & 45 & 4 & 0 & 0 & 0 & 196 \\
$\mathrm{C}_{-4}$ & 0 & 0 & 0 & 0 & 19 & 18 & 24 & 30 & 36 & 42 & 20 & 12 & 3 & 0 & 204 \\
$\mathrm{C}_{-5}$ & 0 & 0 & 0 & 0 & 0 & 27 & 21 & 27 & 33 & 39 & 45 & 4 & 0 & 0 & 196 \\
$\mathrm{C}_{-6}$ & 0 & 0 & 0 & 0 & 0 & 0 & 37 & 24 & 30 & 36 & 42 & 20 & 12 & 3 & 204 \\
$\mathrm{C}_{-7}$ & 0 & 0 & 0 & 0 & 0 & 0 & 0 & 48 & 27 & 33 & 39 & 45 & 4 & 0 & 196 \\
Total & 1 & 12 & 44 & 96 & 170 & 264 & 380 & 516 & 524 & 450 & 327 & 168 & 38 & 6 & 2996 \\
\hline \hline
\end{tabular}

Fonte : (Bassanezi,2012) 


\section{Metodologia em Sala de Aula}

Este trabalho surge como uma pesquisa de natureza aplicada, tendo como objetivo despertar o interesse do alunado pela matemática, a partir da construção de uma maquete do problema do apodrecimento das maçãs confinadas em um bin.

A abordagem deste estudo é qualitativa, ou seja, visa identificar a percepção dos participantes durante a experiência sobre a utilização de materiais concretos em sala de aula. O material foi desenvolvido como uma alternativa de aula de matemática no Ensino Médio e apresentado no Colégio Progressão da cidade de Nova Iguaçu do Estado do Rio de Janeiro, como duas oficinas com duração de 50 minutos cada. Para a realização da mesma, a turma foi dividida em cinco grupos, como na Figura 6, e cada equipe recebeu uma caixa contendo as esferas de isopor necessárias para a construção do modelo e palitos de dente para uni-las, como na Figura 7.

Figura 6: Projeto apresentado no Colegio Progressão
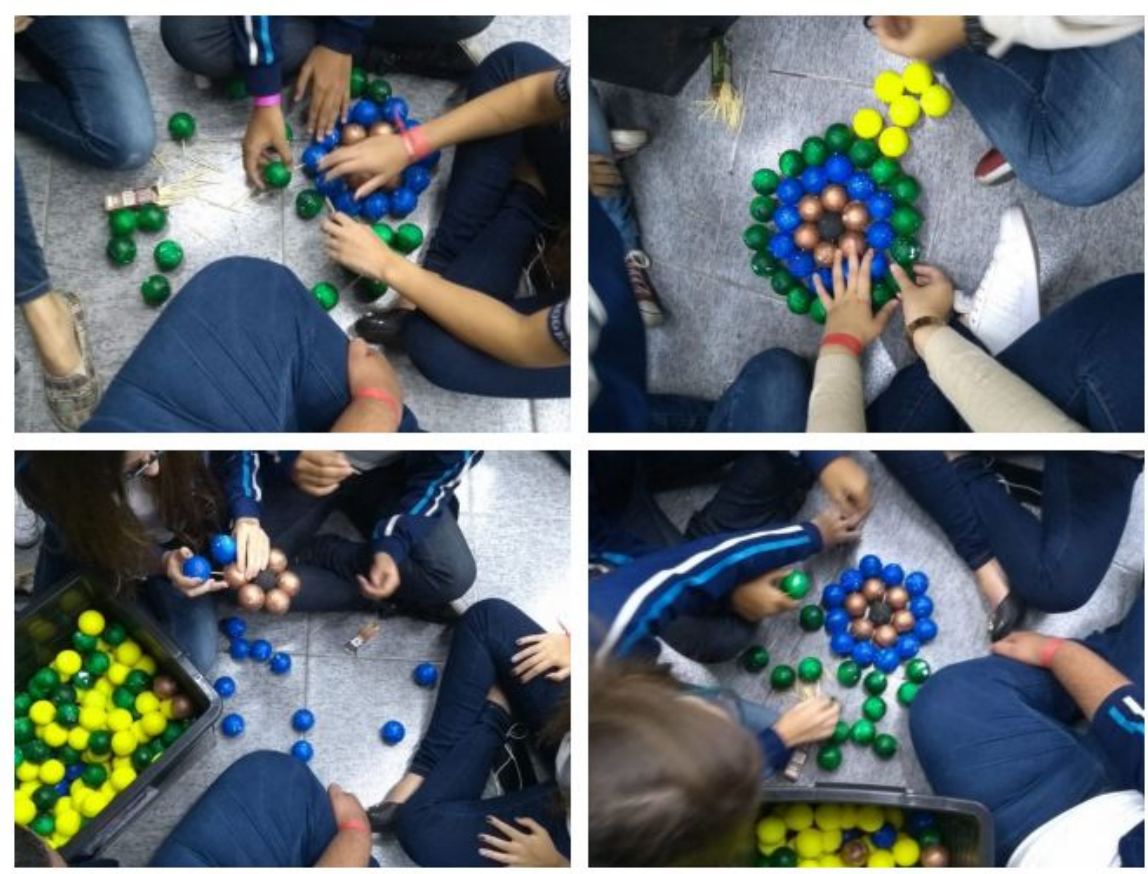

Fonte : Autoria Própria

Durante a primeira etapa da aula, os alunos foram introduzidos aos conceitos básicos de modelagem matemática e para qual propósito ela é utilizada. Os mesmos demonstraram curiosidade pela atividade proposta. 
Figura 7: Maquete do modelo proposto

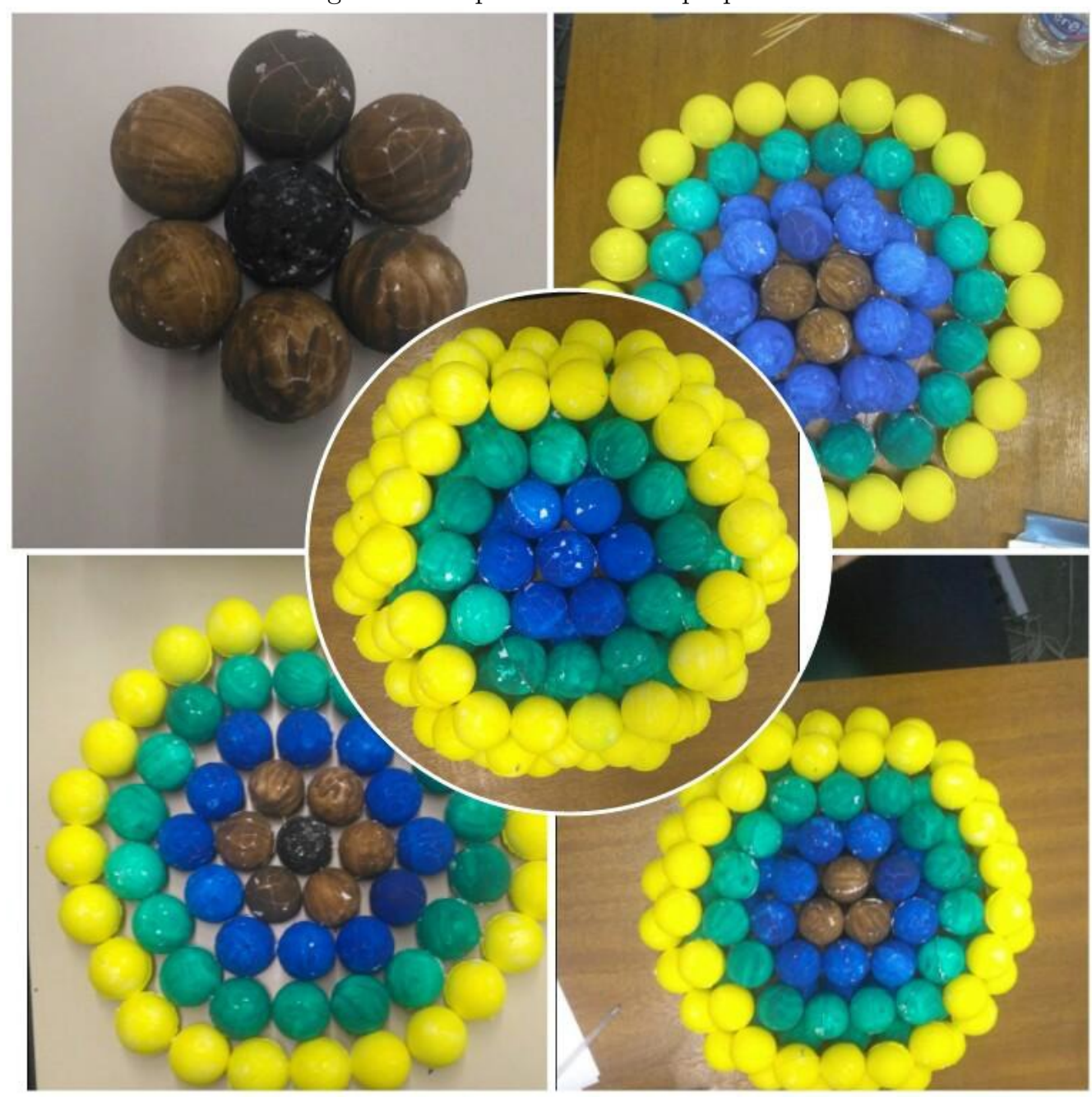

Fonte : Autoria Própria

\section{Resultados Obtidos e Conclusões}

Durante a oficina os alunos demonstraram curiosidade e interesse principalmente ao montar a maquete. Em um primeiro momento, eles foram questionados a saber quantas maçãs ficariam podres em cada estágio. No início o resultado não era o que eles esperavam, porém ao decorrer do processo eles identificaram que se tratava de uma progressão aritmética, demonstrando intuitivamente a fórmula geral desta.

Burak (BURAK, 2004) acredita que a modelagem matemática gera uma mudança de postura por parte do professor e estabelece relações afetivas mais fortes entre os alunos e o mesmo. Na prática, percebe-se o empenho dos alunos ao participarem de uma nova abordagem de conteúdos que eles já 
conheciam. Em ambos momentos, o retorno foi positivo com mais ideias e questionamentos para o enriquecimento da aula.

Ao final da oficina, um questionário com quatro perguntas (como mostra a Figura 8) foi entregue aos alunos, tendo como finalidade colher suas impressões sobre a importância de atividades como essa:

Figura 8: Modelo do questionário utilizado para coletar as impressões dos alunos no final da oficina.

\section{Avaliando a Oficina Dinâmica do Processo de Apodrecimento de Maças}

1) Você gostaria de ter aulas como esta para a apresentaçäo de novos conteúdos?

( ) $\operatorname{sim}$ ( ) nāo

2) Yoce̊ conseguiria identiflcar os conteúdos anteriormente estudados que foram abordados neste trabalho se nāo fossem mencionados ?

\section{( ) $\operatorname{sim}$ ( ) não}

3) Para você, qual o grau de importância de aulas como esta?

( ) $1($ ) 2() 3() 4() 5

4) Deixe aquí uma sugestão, critica ou elogio sobre a oficina:

Fonte : Autoria Própria

Nas duas oficinas, houve a participação de 36 alunos, sendo 20 na primeira e 16 na segunda. Todos responderam às perguntas de 1 a 4 e, com suas respostas, foi possível notar o efeito positivo que a oficina surtiu na maioria deles.

$\mathrm{Na} 1^{\mathrm{a}}$ oficina, dos 20 alunos envolvidos na atividade, 18 responderam que gostariam de ter aulas como aquela para a apresentação de novos conteúdos. Além disso, 15 deles conseguiram identificar conhecimentos já adquiridos por eles inseridos na oficina, antes mesmo que esse conceitos fossem mencionados. Segundo os dados obtidos, notou-se que $75 \%$ da turma atribuiu grau 5 ao nível de importância de aulas como esta.

$\mathrm{Na} 2^{\mathrm{a}}$ oficina, percebeu-se que a maioria também achou a oficina prazerosa, já que apenas 2 dos 
16 alunos disseram que não gostaria de ter aulas como esta para a apresentação de conteúdos. Outro dado interessante é que 15 dos 16 alunos conseguiram perceber conteúdos já aprendidos por eles durante a atividade sem que fossem nomeados. Por fim, 11 estudantes avaliaram o grau de importância de atividades parecidas com esta como 5 .

Um dado importante é que nenhum aluno de nenhuma das duas oficinas deu nota 1 ou 2 para a atividade; apenas 2 dos 36 alunos atribuíram grau 3; e 8 do total de alunos de ambas as oficinas avaliaram seu grau e importância como 4 .

O quarto item do questionário era uma questão qualitativa, para que eles pudessem deixar suas sugestões, elogios e críticas. Ao ler os comentários, pôde-se perceber como o saldo da atividade foi positivo devido a alta aceitação nos comentários. Abaixo apresentamos alguns dos comentários que mostram a opinião dos estudantes:

\section{- Oficina 1}

Comentário 1: "O ensino e apresentação de conteúdos através de experimentações e aproximações com a realidade incentivam a maior absorção, então projetos como estes precisam ser mais explorados e ampliados."

Comentário 2: "Oficinas como esta facilitam a absorção do conteúdo, além de estimular a vontade de aprender mais."

Comentário 3: "É bem interessante, uma forma bem diferente e divertida de aprender."

Comentário 4: "Amei, muito simples porém ótima para melhor aprendizagem."

Comentário 5: "Adorei a aula, pois facilita a visualização do conteúdo que muitas vezes temos dificuldades."

\section{- Oficina 2}

Comentário 1: "Odeio matemática com todas as minhas forças, não tenho facilidade, porém, me senti mais calmo e vi a matemática de uma maneira menos aterrorizante, deveria ter mais aulas com essa, parabéns!"

Comentário 2: "Foi uma ótima forma de abordar o tema porque faz com que os alunos associem a matéria com uma situação real toda vez que for estudá-la. Quanto às críticas, não possuo porque adorei!"

Comentário 3: "Amei a aula, as explicações foram ótimas, já tenho minha revisão para o $2^{\circ}$ bimestre. Vocês arrasaram."

Com isso, vemos que esse tipo de aula deixa o ambiente mais lúdico e, consequentemente, mais interessante para o alunado. A partir dos comentários, percebe-se que o próprio aluno vê essas práticas como uma maneira de auxiliar na compreensão do conteúdo tanto em aulas introdutórias como atividades de fixação. Como cita Rubem Alves, em seu conto "A Arte de Produzir Fome"(ALVES, 2016), um professor deve sempre despertar a vontade de aprender em seus alunos, deixando-os sempre curiosos 
e instingados a adquirir novos conhecimentos; os comentários dos alunos explicitam como a oficina contribuiu para que isso ocorresse.

\section{Referências}

ALVES, Rubem. A arte de produzir fome. Folha de São Paulo, São Paulo, 29 out. 2002. Disponível em: <https://www1.folha.uol.com.br/folha/sinapse/ult1063u146.shtml>. Acesso em: 16 de maio de 2016.

BARBOSA, A. A. de S. Modelagem Matemática: relatos de professores. 2012. 378f. Dissertação (Mestrado em Educação em Ciência e em Matemática), Universidade Federal do Paraná, Curitiba, 2012.

BASSANEZI, Rodney Carlos. Temas e Modelos. Universidade Federal do ABC. Campinas. 2012.

BURAK, Dionísio. Modelagem Matemática e a sala de aula. Encontro Paranaense de Modelagem em Educação Matemática, v. 1, p. 1-10, 2004.

GONTIJO, C. H. Relações entre Criatividade, Criatividade em Matemática e Motivação em Matemática de Alunos do Ensino Médio. 2007. 206f. Tese (Doutorado em Psicologia), Universidade de Brasília, Brasília, 2007. 